\title{
Data Mining Pengelompokan Pasien Rawat Inap Peserta BPJS Menggunakan Metode Clustering (Studi Kasus : RSU.Bangkatan)
}

\author{
Novi Karolina ${ }^{1)}$ \\ 1) Mahasiswa Program Studi Sistem Informasi, STIK KAPUTAMA Binjai \\ Jl. Veteran No. 4A-9A, Binjai 20714, Sumatera Utara \\ www.kaputama.ac.id // E-mail : info@kaputama.ac.id
}

Riwayat : Copyright (C2021, JITU, Submitted: 20 Maret 2021; Revised: 07 Agustus 2021; Accepted: 08 Agustus 2021; Published: 01 September 2021

\begin{abstract}
The system currently used by the hospital is still manual in managing patient data and information, therefore it is necessary to have a Bangkat Binjai Hospital Service system to provide complete and detailed information to hospital patients using BPJS. So in this case the author will design and build a system that will be used in grouping inpatients based on the BPJS Class and the variables determined using the clustering method, so that later it can make it easier for administrators to process data and information on inpatients using BPJS. From the tests carried out using the clustering method with the k-means algorithm, it can be seen that cluster 3 of the criteria for disease type, diagnosis result, and age, the group that has the highest set / value of BPJS Class patient data, namely in Cluster 1 totaling 435 patient data Inpatients using BPJS at the age of 20-39 years and the type of disease are benign tumors, then the BPJS class used is the Level 2 BPJS. Inpatients who use BPJS at the age of 20-39 years and the type of disease is heart complications, then the BPJS class used is BPJS Level 1. And the group that has the highest set / value of BPJS Class patient data, namely Cluster 3 totaling 270 inpatient data. who used BPJS at the age of 20-39 years and the type of disease was uric acid, then the BPJS class was used is BPJS Level 1.
\end{abstract}

Keywords - Data Mining, K-means Algorithm, Inpatient.

Abstrak - Sistem yang digunakan oleh pihak rumah sakit saat ini masih manual dalam mengelola data dan informasi pasien, maka dari itu perlu adanya sistem Pelayanan Rumah Sakit Bangkatan Binjai untuk memberikan informasi yang lengkap dan detail kepada pasien rumahsakit yang menggunakan BPJS. Maka dalam hal ini penulis akan merancang dan membangun sebuah sistem yang akan digunakan dalam pengelompokkan pasien rawat inap berdasarkan Kelas BPJS dan variabel - variabel yang ditentukan dengan menggunakan metode clustering, agar nantinyadapat mempermudah admin dalammengolah data dan informasi pada pasien rawat inap yang menggunakan BPJS. Dari pengujian yang dilakukan menggunakan metode clustering dengan algoritma $k$ -

\footnotetext{
${ }^{*}$ Penulis korespondensi (Novi Karolina)
}

Email: novikarolina383@gmail.com means ini, dapat diketahui cluster 3 dari kriteria jenis penyakit, hasil diagnosa, dan usia, kelompok yang memiliki himpunan/nilai paling tinggi data pasien Kelas BPJS, yaitu pada Cluster 1 berjumlah 435 data pasien rawat inap yang menggunakan BPJS pada Usia20-39 tahun dan jenis penyakitnya adalah Tumor Jinak, kemudian kelas BPJS yang digunakan adalah BPJS Tingkat 2. Dan kelompok yang memiliki himpunan/nilai paling menengah data pasien Kelas BPJS, yaitu pada Cluster 2 berjumlah 395 data pasien rawat inap yang menggunakan BPJS pada Usia20-39 tahun dan jenis penyakitnya adalah komplikasi jantung, kemudian kelas BPJS yang digunakan adalah BPJS Tingkat 1. Dan kelompok yang memiliki himpunan/nilai paling tinggi data pasien KElas BPJS, yaitu pada Cluster 3 berjumlah 270 data pasien rawat inap yang menggunakan BPJS pada Usia20-39 tahun dan jenis penyakitnya adalah asam urat, kemudian kelas BPJS yang digunakan adalah BPJS Tingkat 1.

Kata kunci - Data Mining, Algoritma k-means, Pasien Rawat Inap.

\section{Pendahuluan}

\section{A. Latar Belakang Masalah}

Rumah Sakit Bangkatan adalah salah satu tempat menyelenggarakan upaya kesehatan sarana dan prasarana dengan memperdayakan berbagai kesatuan personel terlatih dan terdidik dalam menghadapi dan menangani masalah medis untuk pemulihan dan pemeliharan kesehatan yang baik. Pelayanan kesehatan Rumah Sakit Bangkatan Binjai sejak awal dibangun hanya berfokus pada karyawan Perkebunan, namun memasuki Era Kemerdekaan hingga sekarang Rumah Sakit ini juga telah melayani pasien umum.[1]

Sistem yang digunakan oleh pihak rumah sakit saat ini masih manual dalam mengelola data dan informasi pasien, maka dari itu perlu adanya sistem Pelayanan Rumah Sakit Bangkatan Binjai untuk memberikan informasi yang lengkap dan detail kepada pasien rumah sakit yang menggunakan BPJS. Beberapa pasien rawat inap sudah menggunakan fasilatas BPJS dengan berbagai macam penyakit yang diderita oleh pasien untuk melakukan pemeriksaan lebih lanjut agar dapat sembuh 
dari penyakit yang diderita. Dengan adanya data dan informasi yang tertinggal dalam bentuk dokumen berupa, nama pasien, usia, jenis penyakit, dan kelas BPJS.

Maka dalam hal ini penulis akan merancang dan membangun sebuah sistem yang akan digunakan dalam pengelompokkan pasien rawat inap berdasarkan Kelas BPJS dan variabel - variabel yang ditentukan dengan menggunakan metode clustering, agar nantinya dapat mempermudah admin dalam mengolah data dan informasi pada pasien rawat inap yang menggunakan BPJS.[2][3]

Penelitian ini diperkuat oleh Jurnal Teknik Informatika, Unika Santo Thomas (JTIUST), Vol01 No 02, Desember 2016 yang ditulis oleh Parasian D P Silitonga, S.Kom., dkk dengan judul "Implementasi Algoritma K-Means Clustering Pada Analisis Penyebaran Penyakit Pasien Pengguna Badan Penyelenggara Jaminan Sosial Kesehatan (BPJS) (Studi Kasus : Rumah Sakit Umum Pusat Haji Adam Malik Medan)" yang menyatakan bahwa tujuan untuk menemukan kecenderungan penyakit pada sekelompok orang yang pergi ke Rumah Sakit Haji Adam Malik di Medan, dan diharapkan dapat digunakan sebagai areferensi untuk program pendidikan kesehatan sekaligus dapat menjadi antisipasi layanan prioritas bagi pasien khususnya pengguna BPJS.[10]

\section{B. Rumusan Masalah}

Berdasarkan latar belakang masalah diatas dijelaskan, maka penulis dapat merumuskan masalah sebagai berikut:

1. Bagaimana cara menganalisis data yang dapat memberikan informasi mengenai pasien rawat inap berdasarkan kelas BPJS menggunakan algoritma $K$ Means?

2. Bagaimana membuat aplikasi yang dapat memberikan informasi dengan cepat mengenai data tentang pasien rawat inap berdasarkan kelas BPJS?

3. Bagaimana menerapkan algoritma K-Means dalam mengolah tumpukan data tentang pasien rawat inap berdasarkan kelas BPJS?

\section{Batasan Masalah}

Dalam menyelesaikan masalah, perlu dibuat suatu batasan agar tidak menyimpang dari pokok permasalah. Oleh karena itu, batasan yang dibuat dalam permasalahan ini adalah sebagai berkut:

1. Metode yang digunakan adalah metode clustering (penglompokkan) dengan algoritma $K$-Means dan Software yang digunakan MATLAB versi 7.7.0 (2008).

2. Variabel yang akan digunakan yaitu : usia, jenis penyakit, kelas BPJS.

3. Data yang digunakan adalah data tahun 2014- 2019

\section{Tujuan Penelitian}

Berdasarkan pemaparan diatas, tujuan dari penelitian ini adalah sebagai berikut :
1. Untuk mengetahui hasil dari pengolahan data pasien dan menghasilkan informasi pasien rawat inap berdasarkan Kelas BPJS.

2. Untuk mengetahui hasil dari penerapan Algoritma $K$ Meanspada pasien rawat inap berdasarkan Kelas BPJS.

3. Untuk merancang dan membangun sebuah sistem pada pengelompokkan pasien rawat inap berdasarkan variable

\section{E. Manfaat Penelitian}

Adapun manfaat yang didapat dari penyusunan skripsi ini adalah:

1. Dapat menganalisis data mengenai pasien rawat inap berdasarkan kelas BPJS menggunakan algoritma $K$ Means.

2. Dapat memberikan informasi tentang jenis penyakit pada pasien rawat inap berdasarkan Kelas BPJS.

3. Dapat mengetahui bagaimana mengelompokkan (cluster) data dengan menggunakan metode clustering dan algoritma K-Means.

\section{Metodologi Penelitian}

\section{A. Penelitian Terdahulu}

Berdasarkan Berdasarkan Jurnal Teknik Informatika, Unika Santo Thomas (JTIUST), Vol01 No 02, Desember 2016 yang ditulis oleh Parasian D P Silitonga, S.Kom., dkk dengan judul "Implementasi Algoritma K-Means Clustering Pada Analisis Penyebaran Penyakit Pasien Pengguna Badan Penyelenggara Jaminan Sosial Kesehatan (BPJS) (Studi Kasus : Rumah Sakit Umum Pusat Haji Adam Malik Medan)" yang menyatakan bahwa tujuan untuk menemukan kecenderungan penyakit pada sekelompok orang yang pergi ke Rumah Sakit Haji Adam Malik di Medan, dan diharapkan dapat digunakan sebagai areferensi untuk program pendidikan kesehatan sekaligus dapat menjadi antisipasi layanan prioritas bagi pasien khususnya pengguna BPJS.[10]

\section{B. Pengertian Data Mining}

Data mining adalah proses yang menggunakan teknik statistic, matematika, kecerdasan buatan dan pembelajaran mesin (machine learning) mengekstrasi dan mengidentifikasi informasi yang bermanfaat dan pengetahuan yang terkait dari berbagai database yang terkait.[11][12]

\section{Pengertian BPJS}

Badan Penyelenggara Jaminan Sosial (BPJS) adalah badan hukum yang dibentuk dengan Undang-Undang untuk menyelenggarakan perogram jaminan sosial. BPJS menurut UU Nomor 40 Tahun 2004 Tentang Sistem Jaminan Sosial Nasional adalah trasformasi dari badan penyelenggara jaminan sosial yang sekarang telah berjalan dan dimungkinkan untuk membentuk badan penyelenggara baru sesuai dengan dinamika 
perkembangnan jaminan sosial.BPJS Kesehatan adalah badan hukum publik menurut UU BPJS.

\section{Pengertian Clustering}

Clustering merupakan salah satu metode Data Mining yang bersifat tanpa arahan (unsupervised) Ada dua jenis data clustering yang sering dipergunakan dalam proses penglompokkan data yaitu hierarchical (hirarki) data clustering dan non-hierarchical (non hirarki) data clustering.

\section{E. Algoritma K-means}

Algoritma K-means merupakan algoritma yang relative sederhana untuk mengklasifikasikan atau mengelompokkan sejumlah besar objek dengan atribut tertentu kedalam kelompok-kelompok (cluster) sebanyak $\mathrm{K}$, pada algoritma $\mathrm{K}$-means jumlah cluster $\mathrm{K}$ sudah ditentukan lebih dahulu.

\section{F. Pengertian MATLAB}

Matlab merupakan perangkat lunak yang cocok dipakai sebagai alat komputasi yang melibatkan penggunaan matriks dan vektor, fungsi-fungsi dalam toolbox matlab dibuat untuk memudahkan perhitungan tersebut.

\section{Perancangan}

\section{A. Analisa Rancangan}

Dalam proses penelitian ini ditujukkan untuk lebih memberikan hasil yang berarti untuk pihak yang terkait dalam menangangi pengelompokkan agar tidak terjadi kesalahan dalam pengelompokkan pasien rawat inap peserta BPJS. Untuk itu, peneliti melakukan pengelompokkan pasien rawat inap peserta BPJS untuk mengatasi permasalahan dalam data yang terjadi dalam pelayanan informasi yang diberikan.[6][7][8][9]

1. Identifikasi Masalah

Tahap ini merupakan tahapan awal dalam penelitian yaitu menentukan latar belakang masalah, tujuan dan manfaat penelitian agar tidak keluar dari pembahasan.

\section{Kajian Teori}

Tahap ini adalah mencari informasi, sumber-sumber yang berkaitan dengan masalah yang dihadapi baik dari studi pustaka, jurnal dan internet sebagai pendukung dan landasan dasar penulisan skripsi.

3. Pengumpulan Data

Tahap ini dilakukan pengumpulan data-data pendukung dan data-data utama yang dibutuhkan dalam proses perancangan sistem mengenai data data tersebut diperoleh dari data pasien rawat inap di RSU Bangkatan Binjai.

4. Analisa Data

Tahap ini merupakan tahapan mengolah dan menganalisa data yang telah diperoleh sehingga data tersebut dapat dikelompokkan sesuai dengan variabel yang ditentukan.

5. Pengujian dan Implementasi
Tahap ini merupakan tahapan yang melakukan pengujian validasi dan implementasi data yang telah dianalisa sebelumnya serta penyusunan program.

6. Evaluasi

Tahap ini merupakan tahap mengambil kesimpulan dan saran yang dapat dilakukan dalam penyusunan skripsi. Dengan adanya kesimpulan maka diketahui hasil dari keseluruhan skripsi dan diharapkan dengan saran akan ada perbaikan-perbaikan dan manfaat bagi yang lain

\section{B. Perancangan Flowchart}

K-means adalah algoritma clustering yang paling populer dan banyak digunakan dalam dunia industri. Algoritma ini disusun atas dasar ide yang sederhana, pada awalnya ditentukan beberapa cluster yang akan dibentuk lalu sembarang obyek atau elemen pertama dalam cluster dapat dipilih untuk dijadikan sebagai titik tengah (centroid point) cluster.

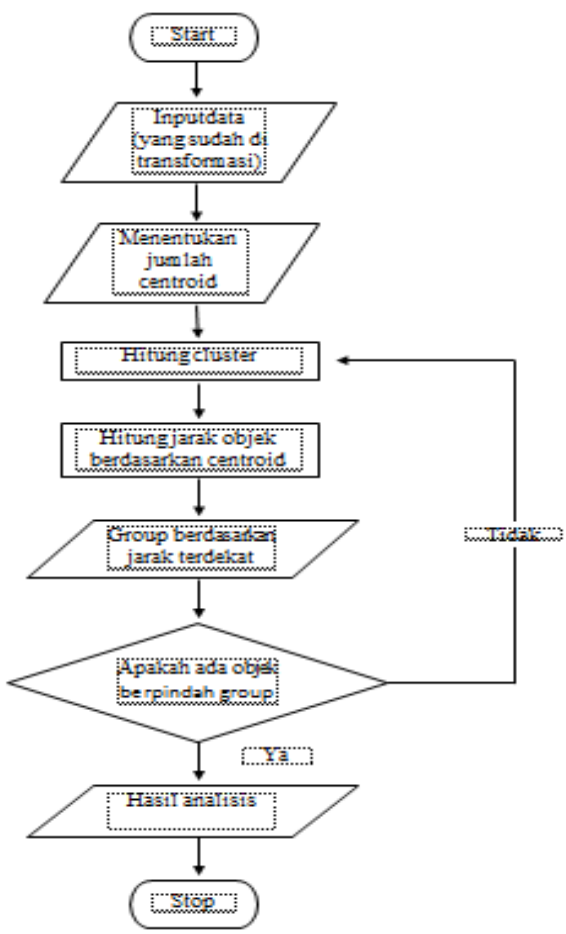

Gambar 2. Flowchart untuk sistem yang akan dirancang

\section{Data Pendukung Penelitian}

Tabel 1. Data pasien

\begin{tabular}{cccc}
\hline No & Usia & Jenis penyakit & Kelas BPJS \\
\hline 1 & $\begin{array}{c}10 \\
\text { tahun }\end{array}$ & Usus Buntu & BPJS Tingkat 3 \\
\hline 2 & $\begin{array}{c}35 \\
\text { tahun }\end{array}$ & $\begin{array}{c}\text { Artritis/ } \\
\text { Rematik }\end{array}$ & BPJS Tingkat 1 \\
\hline 3 & $\begin{array}{c}18 \\
\text { tahun }\end{array}$ & Demam Tinggi & BPJS Tingkat 2 \\
\hline 4 & $\begin{array}{c}30 \\
\text { tahun }\end{array}$ & Tumor Jinak & BPJS Tingkat 1 \\
\hline
\end{tabular}




\begin{tabular}{|c|c|c|c|}
\hline 5 & $\begin{array}{c}29 \\
\text { tahun }\end{array}$ & Lupus & BPJS Tingkat 3 \\
\hline 6 & $\begin{array}{c}35 \\
\text { tahun }\end{array}$ & Bersalin & BPJS Tingkat 3 \\
\hline 7 & $\begin{array}{c}45 \\
\text { tahun }\end{array}$ & Stroke & BPJS Tingkat 1 \\
\hline 8 & $\begin{array}{c}38 \\
\text { tahun }\end{array}$ & Asam Urat & BPJS Tingkat 2 \\
\hline 9 & $\begin{array}{c}20 \\
\text { tahun }\end{array}$ & Tumor Jinak & BPJS Tingkat 2 \\
\hline 10 & $\begin{array}{c}50 \\
\text { tahun }\end{array}$ & Asam Urat & BPJS Tingkat 1 \\
\hline 11 & $\begin{array}{c}31 \\
\text { tahun }\end{array}$ & Tumor Tulang & BPJS Tingkat 3 \\
\hline 12 & $\begin{array}{c}15 \\
\text { tahun }\end{array}$ & Usus Buntu & BPJS Tingkat 3 \\
\hline 13 & $\begin{array}{c}30 \\
\text { tahun }\end{array}$ & Patah Tulang & BPJS Tingkat 3 \\
\hline 14 & $\begin{array}{c}14 \\
\text { tahun }\end{array}$ & THT & BPJS Tingkat 1 \\
\hline 15 & $\begin{array}{c}50 \\
\text { tahun }\end{array}$ & $\begin{array}{c}\text { Sakit Gigi dan } \\
\text { Mulut }\end{array}$ & BPJS Tingkat 1 \\
\hline 16 & $\begin{array}{c}22 \\
\text { tahun }\end{array}$ & Infeksi Jamur & BPJS Tingkat 1 \\
\hline 17 & $\begin{array}{c}55 \\
\text { tahun }\end{array}$ & $\begin{array}{c}\text { Oprasi Kecil } \\
\text { Mata }\end{array}$ & BPJS Tingkat 2 \\
\hline 18 & $\begin{array}{c}60 \\
\text { tahun }\end{array}$ & Jantung & BPJS Tingkat 3 \\
\hline 19 & $\begin{array}{c}45 \\
\text { tahun }\end{array}$ & $\begin{array}{c}\text { Oprasi Kecil } \\
\text { Mata }\end{array}$ & BPJS Tingkat 1 \\
\hline 20 & $\begin{array}{c}21 \\
\text { tahun }\end{array}$ & Usus Buntu & BPJS Tingkat 2 \\
\hline
\end{tabular}

Tabel 2. Inisialisasi Kriteria Usia

\begin{tabular}{cc}
\hline Kode & Usia \\
\hline 1 & $0-19$ Tahun \\
\hline 2 & $20-39$ Tahun \\
\hline 3 & $20-59$ Tahun \\
\hline 4 & $\geq 60$ Tahun \\
\hline
\end{tabular}

Tabel 3. Jenis Penyakit

\begin{tabular}{cc}
\hline Kode & Jenis Penyakit \\
\hline 1 & Astritis / Rematik \\
\hline 2 & Lupus \\
\hline 3 & Asam Urat \\
\hline 4 & Sakit Gigi dan Mulut \\
\hline 5 & Infeksi Jamur \\
\hline 6 & Usus Buntu \\
\hline 7 & Tumor Jinak \\
\hline 8 & Demam tinggi \\
\hline 9 & Bersalin \\
\hline 10 & THT \\
\hline 11 & Operasi Kecil Mata \\
\hline 12 & Jantung \\
\hline 13 & Tumor Tulang \\
\hline 14 & Patah Tulang \\
\hline 15 & Strok \\
\hline 16 & Ginjal
\end{tabular}

Tabel 4. Data Kelas BPJS

\begin{tabular}{cc}
\hline Kode & Kelas BPJS \\
\hline 1 & BPJS Tingkat 1 \\
\hline 2 & BPJS Tingkat 2 \\
\hline 3 & BPJS Tingkat 3 \\
\hline
\end{tabular}

Tabel 5. Transformasi Data

\begin{tabular}{ccccc}
\hline No & Nama & $\begin{array}{c}\text { Usia } \\
(\mathbf{X})\end{array}$ & $\begin{array}{c}\text { Jenis } \\
\text { Penyakit } \\
(\mathbf{Y})\end{array}$ & $\begin{array}{c}\text { Kelas } \\
\text { BPJS } \\
(\mathbf{Z})\end{array}$ \\
\hline 1 & $\mathrm{~A}$ & 1 & 6 & 3 \\
\hline 2 & $\mathrm{~B}$ & 2 & 1 & 1 \\
\hline 3 & $\mathrm{C}$ & 1 & 8 & 2 \\
\hline 4 & $\mathrm{D}$ & 2 & 7 & 1 \\
\hline 5 & $\mathrm{E}$ & 2 & 2 & 3 \\
\hline 6 & $\mathrm{~F}$ & 2 & 9 & 3 \\
\hline 7 & $\mathrm{G}$ & 3 & 15 & 1 \\
\hline 8 & $\mathrm{H}$ & 3 & 3 & 2 \\
\hline 9 & $\mathrm{I}$ & 2 & 7 & 2 \\
\hline 10 & $\mathrm{~J}$ & 3 & 3 & 1 \\
\hline 11 & $\mathrm{~K}$ & 2 & 13 & 3 \\
\hline 12 & $\mathrm{~L}$ & 1 & 6 & 3 \\
\hline 13 & $\mathrm{M}$ & 2 & 14 & 3 \\
\hline 14 & $\mathrm{~N}$ & 1 & 10 & 1 \\
\hline 15 & $\mathrm{O}$ & 3 & 4 & 1 \\
\hline 16 & $\mathrm{P}$ & 2 & 5 & 1 \\
\hline 17 & $\mathrm{Q}$ & 3 & 11 & 2 \\
\hline 18 & $\mathrm{R}$ & 4 & 12 & 3 \\
\hline 19 & $\mathrm{~S}$ & 3 & 11 & 1 \\
\hline 20 & $\mathrm{~T}$ & 2 & 6 & 2 \\
\hline & & & & \\
\hline
\end{tabular}

Tabel 6. Hasil Perhitungan Iterasi 1

\begin{tabular}{|l|c|c|c|c|c|c|c|l|}
\hline No & Nama & Usia & $\begin{array}{c}\text { Jenis } \\
\text { Penyakit }\end{array}$ & $\begin{array}{c}\text { Kelas } \\
\text { BPJS }\end{array}$ & $\begin{array}{c}\text { Jarak } \\
\text { Dari } \\
\text { Cl }\end{array}$ & $\begin{array}{c}\text { Jarak } \\
\text { Dari } \\
\text { C2 }\end{array}$ & $\begin{array}{c}\text { Jarak } \\
\text { Dari } \\
\text { C3 }\end{array}$ & Group \\
\hline & & X & Y & Z & & & & \\
\hline 1 & A & 1 & 6 & 3 & 2,45 & 3,74 & 2,45 & 3 \\
\hline 2 & B & 2 & 1 & 1 & 6 & 2,45 & 4 & 2 \\
\hline 3 & C & 1 & 8 & 2 & 1,73 & 5,39 & 3,32 & 1 \\
\hline 4 & D & 2 & 7 & 1 & 0 & 4,24 & 2 & 1 \\
\hline 5 & E & 2 & 2 & 3 & 5,39 & 1,73 & 3,61 & 2 \\
\hline 6 & F & 2 & 9 & 3 & 2,83 & 6,16 & 4,47 & 1 \\
\hline 7 & G & 3 & 15 & 1 & 8,06 & 12,04 & 10,05 & 1 \\
\hline 8 & H & 3 & 3 & 2 & 4,24 & 0 & 2,45 & 2 \\
\hline 9 & I & 2 & 7 & 2 & 1,00 & 4,12 & 2,24 & 1 \\
\hline 10 & J & 3 & 3 & 1 & 4,12 & 1,00 & 2,24 & 2 \\
\hline 11 & $\mathrm{~K}$ & 2 & 13 & 3 & 6,32 & 10,10 & 8,25 & 1 \\
\hline 12 & $\mathrm{~L}$ & 1 & 6 & 3 & 2,45 & 3,74 & 2,45 & 3 \\
\hline 13 & $\mathrm{M}$ & 2 & 14 & 3 & 7,28 & 11,09 & 9,22 & 1 \\
\hline 14 & $\mathrm{~N}$ & 1 & 10 & 1 & 3,16 & 7,35 & 5,10 & 1 \\
\hline 15 & $\mathrm{O}$ & 3 & 4 & 1 & 3,16 & 1,41 & 1,41 & 3 \\
\hline 16 & $\mathrm{P}$ & 2 & 5 & 1 & 2,00 & 2,45 & 0 & 3 \\
\hline 17 & $\mathrm{Q}$ & 3 & 11 & 2 & 4,24 & 8 & 6,16 & 1 \\
\hline 18 & $\mathrm{R}$ & 4 & 12 & 3 & 5,74 & 9,11 & 7,55 & 1 \\
\hline 19 & $\mathrm{~S}$ & 3 & 11 & 1 & 4,12 & 8,06 & 6,08 & 1 \\
\hline 20 & $\mathrm{~T}$ & 2 & 6 & 2 & 1,41 & 3,16 & 1,41 & 3 \\
\hline 1 & & & & & & & & \\
\hline
\end{tabular}

Keterangan:

1. Jika pada centroid 1 lebih kecil maka hasil cluster masuk pada grup 1.

2. Jika pada centroid 2 lebih kecil maka hasil cluster masuk pada grup 2 . 
3. Jika pada Jika pada centroid 3 lebih kecil maka hasil cluster masuk pada grup 3.

Group lama :

$\{0,0,0,0,0,0,0,0,0,0,0,0,0,0,0,0,0,0,0,0\}$

Group baru :

$\{3,2,1,1,2,1,1,2,1,2,1,3,1,1,3,3,1,1,1,3\}$

Tabel 7. Hasil Perhitungan Iterasi 2

\begin{tabular}{|l|c|c|c|c|c|c|c|c|}
\hline No & Nama & Usia & $\begin{array}{c}\text { Jenis } \\
\text { Penyakit }\end{array}$ & $\begin{array}{c}\text { Kelas } \\
\text { BPJS }\end{array}$ & $\begin{array}{c}\text { Jarak } \\
\text { Dari } \\
\text { C1 }\end{array}$ & $\begin{array}{c}\text { Jarak } \\
\text { Dari } \\
\text { C2 }\end{array}$ & $\begin{array}{c}\text { Jarak } \\
\text { Dari } \\
\text { C3 }\end{array}$ & Group \\
\hline & & X & Y & Z & & & & \\
\hline 1 & A & 1 & 6 & 3 & 4,91 & 4,23 & 1,41 & 3 \\
\hline 2 & B & 2 & 1 & 1 & 9,69 & 1,54 & 4,52 & 2 \\
\hline 3 & C & 1 & 8 & 2 & 2,93 & 5,95 & 2,72 & 3 \\
\hline 4 & D & 2 & 7 & 1 & 3,78 & 4,83 & 1,90 & 3 \\
\hline 5 & E & 2 & 2 & 3 & 8,70 & 1,37 & 3,55 & 2 \\
\hline 6 & F & 2 & 9 & 3 & 1,94 & 6,88 & 3,74 & 1 \\
\hline 7 & G & 3 & 15 & 1 & 4,54 & 12,78 & 9,73 & 1 \\
\hline 8 & H & 3 & 3 & 2 & 7,67 & 0,94 & 2,68 & 2 \\
\hline 9 & I & 2 & 7 & 2 & 3,65 & 4,78 & 1,61 & 3 \\
\hline 10 & J & 3 & 3 & 1 & 7,74 & 1,17 & 2,86 & 2 \\
\hline 11 & K & 2 & 13 & 3 & 2,58 & 10,83 & 7,67 & 1 \\
\hline 12 & L & 1 & 6 & 3 & 4,91 & 4,23 & 1,41 & 3 \\
\hline 13 & M & 2 & 14 & 3 & 3,52 & 11,83 & 8,66 & 1 \\
\hline 14 & N & 1 & 10 & 1 & 1,74 & 7,93 & 4,77 & 1 \\
\hline 15 & O & 3 & 4 & 1 & 6,75 & 1,97 & 2,10 & 3 \\
\hline 16 & P & 2 & 5 & 1 & 5,73 & 2,89 & 1,10 & 3 \\
\hline 17 & Q & 3 & 11 & 2 & 0,81 & 8,77 & 5,73 & 1 \\
\hline 18 & R & 4 & 12 & 3 & 2,42 & 9,94 & 7,03 & 1 \\
\hline 19 & S & 3 & 11 & 1 & 1,29 & 8,80 & 5,81 & 1 \\
\hline 20 & T & 2 & 6 & 2 & 4,64 & 3,79 & 0,63 & 3 \\
\hline
\end{tabular}

Group lama :

$\{3,2,1,1,2,1,1,2,1,2,1,3,1,1,3,3,1,1,1,3\}$

Group baru :

$\{3,2,3,3,2,1,1,2,3,2,1,3,1,1,3,3,1,1,1,3\}$

Tabel 8. Hasil Perhitungan Iterasi 3

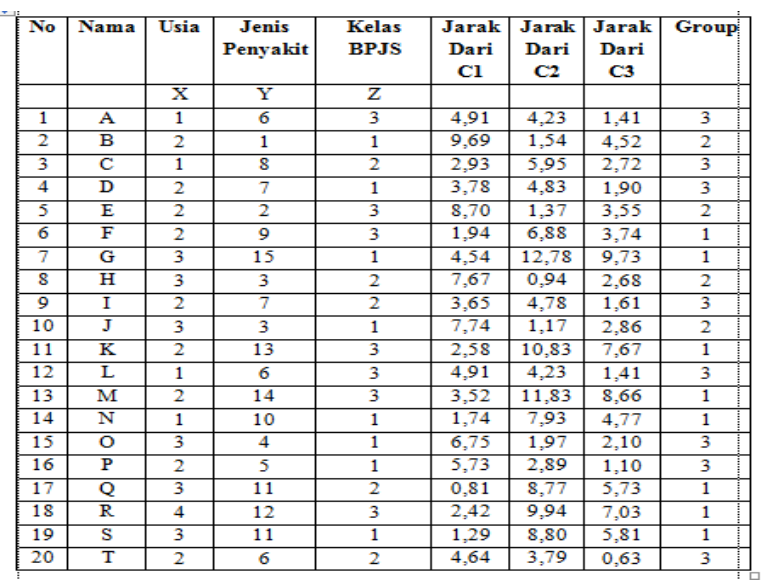

Group lama :

$\{3,2,3,3,2,1,1,2,3,2,1,3,1,1,3,3,1,1,1,3\}$

Group baru :

$\{3,2,3,3,2,1,1,2,3,2,1,3,1,1,3,3,1,1,1,3\}$

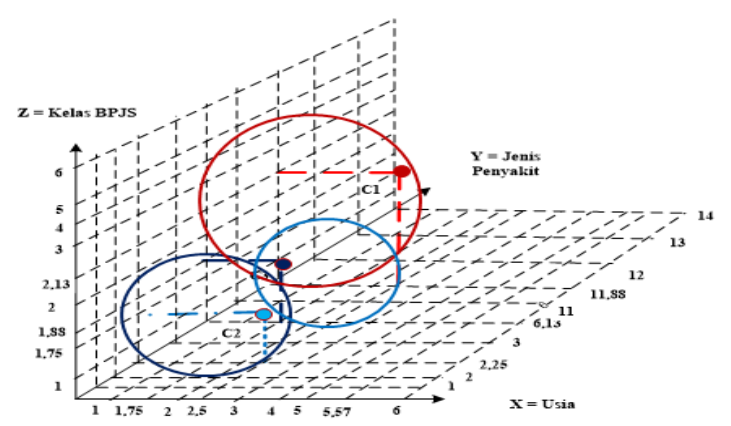

Gambar 3. Grafik Hasil Clustering
Cluster $1: 2,5 ; \quad 11.88 ; \quad 2.13$;

Cluster $2: 2.5 ; \quad 2,25 ; \quad 1.75$

Cluster $3: 1.75 ; \quad 6,13 ; \quad 1,88$

\section{HASIL DAN PEMBAHASAN}

\section{A. Sistem Perancangan Proses Pembahasan}

Langkah-langkah yang dilakukan untuk perhitungan data penglompokkan pasien rawat inap peserta BPJSmenggunakan metode clustering dengan algoritma $K$-means ini, agar dapat dihasilkan sebuah pengetahuan baru, mengenai berapa banyak kelompok data usia, jenis penyakit, kelas BPJS.

1. Menu Home / Menu Utama disini menampilkan interface awal yang berisi Proses Clustering.

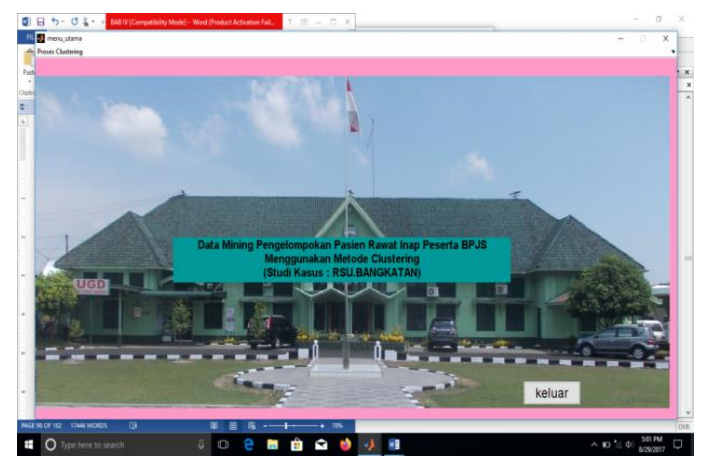

Gambar 4. Menu Home

2. Menu Proses Clustering, disini akan terlihat keseluruhan proses data mining sampai pada pemunculan grafik dan keterangan centroid sebagai hasil dari perhitungan dengan menggunakan metode clustering menggunakan algoritma $k$-means.

a. Gambar 2 Cluster

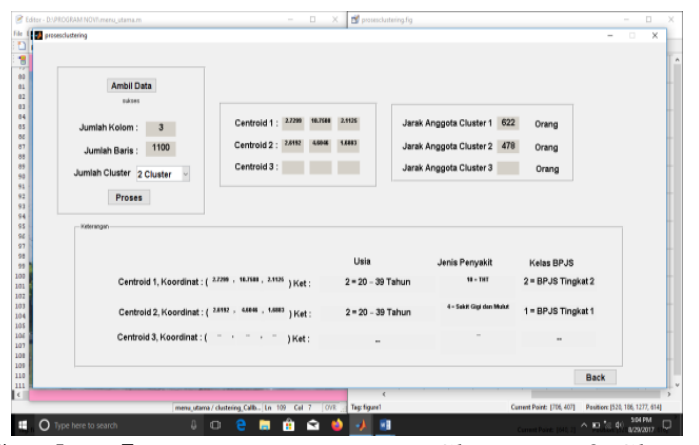

Gambar 5. Form Menu Proses Clustering 2 Cluster

b. Gambar 3 Cluster

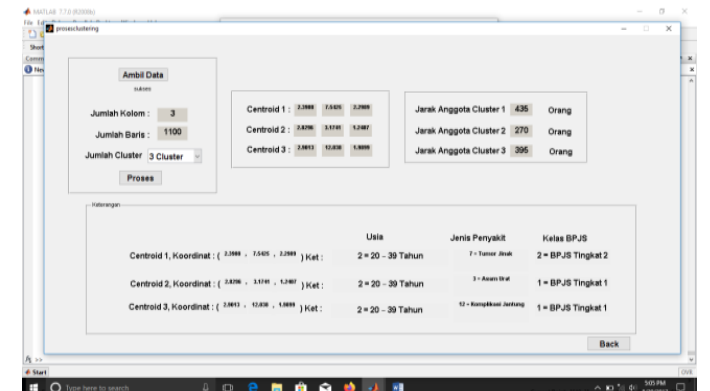

Gambar 6. Form Menu Proses Clustering 3 Cluster 


\section{B. Implementasi}

Implementasi disini merupakan kegiatan dimana data-data yang sudah ditransformasikan diterapkan kedalam perograman yang digunakan dan diproses sejauh mana kinerja sistem dalam mengolah data dan dihasilkan informasi sesuai dengan kebutuhan pengguna. Selain

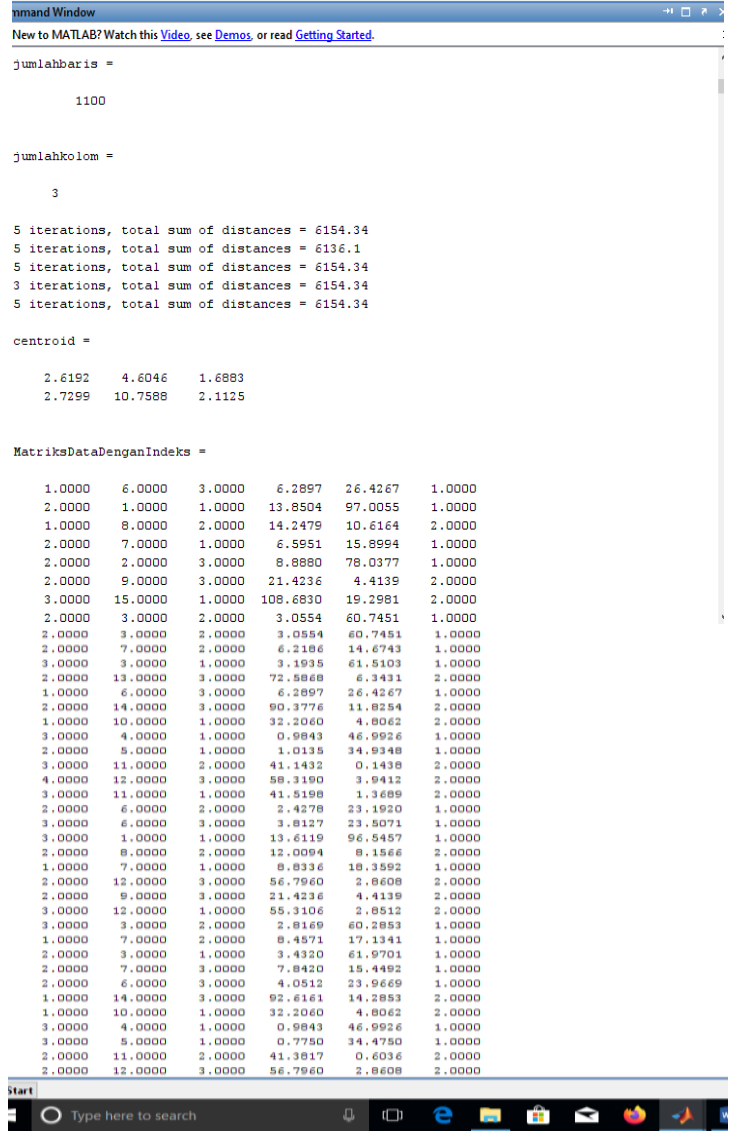

Gambar 7. Jendela Matlab Menampilkan Iterasi Yang Terjadi Dan Hasil Group

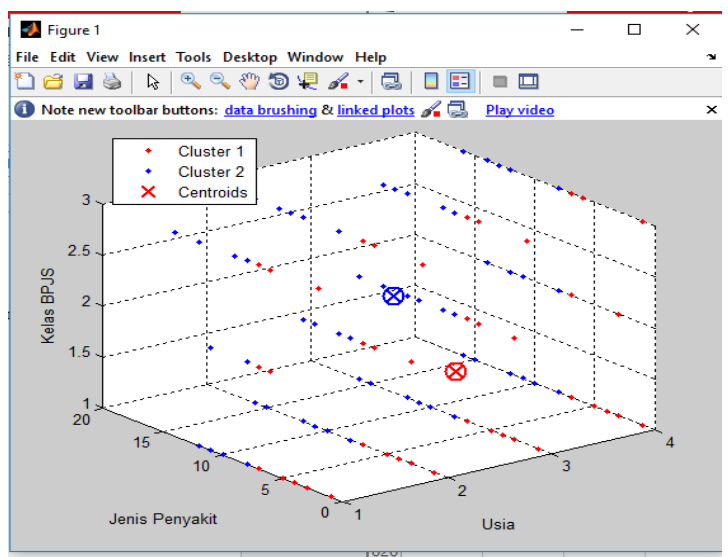

Gambar 8. Grafik Hasil Perhitungan Cluster 2 Berdasarkan data pelangga

Pusatnya $=$

2 (2.62) $\mathbf{4}(4,60) \quad \mathbf{1}(1,69)$

$2(2.73) 2(10,76) 2(2.11)$

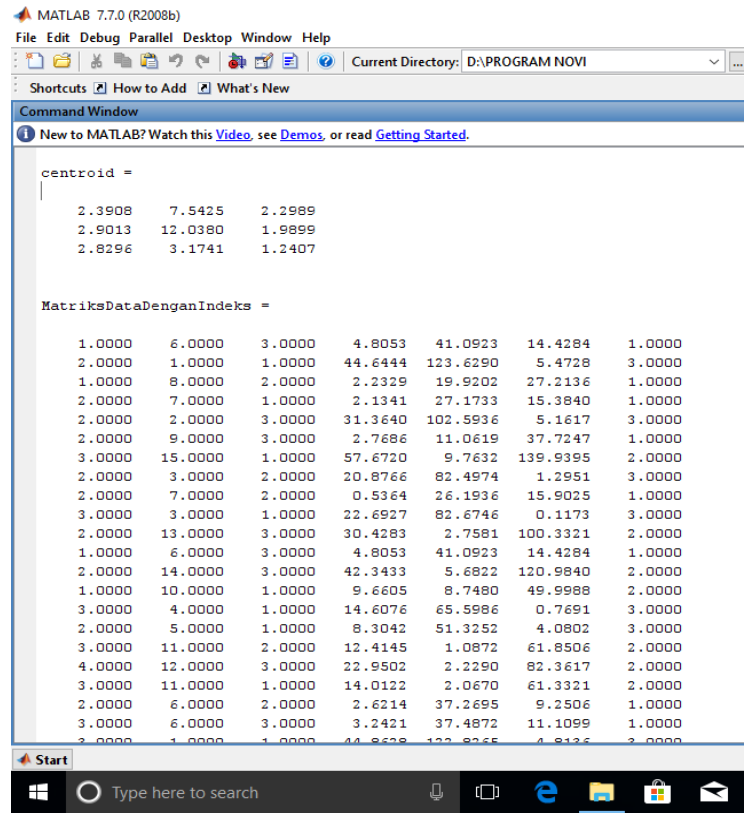

Gambar 9. Jendela Matlab Menampilkan Iterasi yang Terjadi dan Hasil Group

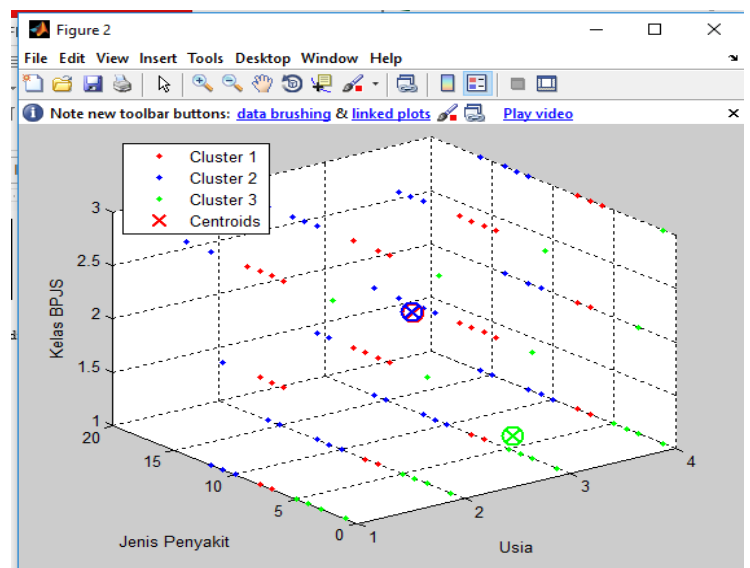

Gambar 10. Grafik Hasil Perhitungan Cluster 3 Berdasarkan Data Pelanggan

Pusatnya $=$

$\begin{array}{lll}2(2.83) & 7(7,54) & 2(2,30) \\ 2(2.90) & 12(12,04) & 1(1,99) \\ 2(2.83) & 3(3,17) & 1(1.24)\end{array}$

\section{KESIMPULAN DAN SARAN}

\section{A. Kesimpulan}

Dari pengujian yang dilakukan menggunakan metode clustering dengan algoritma $k$-means ini, dapat diketahui cluster 2 dari kriteria Usia, Jenis Penyakit, Kelas BPJS, kelompok yang memiliki himpunan/nilai paling tinggi dan paling banyak data pasien kelas BPJS, yaitu pada Cluster 2 berjumlah 622 data pasien dan pada cluster 1 pada group pasien yang menggunakan BPJS pada pasien jenis 
penyakitnya adalah sakit gigi dan mulut, kemudian kelas BPJS yang digunakan adalah BPJS Tingkat 1.

Dan dapat diketahui cluster 3 dari kriteria jenis penyakit, hasil diagnosa, danusia, kelompok yang memiliki himpunan/nilai paling tinggi dan paling menengah data pasien yang mengalami penunggakan, yaitu pada Cluster 1berjumlah435data pasienrawatinapyang menggunakan BPJS pada jenis penyakitnya adalah Tumor Jinak, kemudian kelas BPJS yang digunakan adalah BPJS Tingkat 2. Dari pengujian tersebut juga dapat diketahui bahwa pihak instansi dapat menyusun strategi lebih lanjut dalam mengatasi masalah data pasien rawat inap dirumah sakit.

\section{B. Saran}

Berdasarkan kesimpulan diatas, maka terdapat beberapa saran yang penulis sampaikan agar penulisan skripsi yang bertopik sama menjadi lebih baik dan berguna dimasa yang akan datang. Diantaranya adalah :

1. Diharapkan interface yang dihasilkan dapat lebih berkembang lagi dengan menampilkan perhitungan langsung pada program yang dibangun.

2. Diharapkan dapat menambah lagi kriteria atau variabelnya, agar dapat diketahui hubungan lebih jelas lagi antara variabelnya.

\section{DAFTAR PUSTAKA}

[1] Adi Nugroho. 2005. Analisis dan Perancangan Sistem Informasi Dengan Metodologi Berorientasi Objek. Informatika. Bandung.

[2] B, Indra Yatini. (2010). Flowchart, Algoritma dan Pemrogaman Menggunakan Bahasa C++ Builder. Yogyakarta : Penerbit Graha Ilmu.

[3] Eko Prasetyo. (2014). Data Mining Mengolah Data Menjadi Informasi.

[4] Menggunakan Matlab. Yogyakarta: Andi Offset.

[5] Fajar Astuti Hermawati. (2013). Data Mining. Yogyakarta: Andi Offset

[6] Hend. (2006). Pengertian Unified Modeling Language (UML). Dipetik Oktober 05, 2015, darihttp://adwintaactivity.blogspot.co.id/2012/0 4/definisi-unified-modeling-language-uml.html.

[7] Muningsih, E., \& Kiswati, S. (2015). Penerapan Metode K-Means Untuk Clustering Produk Online Shop. Jurnal Bianglala Informatika..

[8] Prasetyo, Eko.2012.Data Mining Konsep dan Aplikasi Menggunakan Matlab.Yogyakarta:
Andi

[9] Santosa, Budi. 2007. "Data mining terapan dengan MATLAB". Yogyakarta Graha Ilmui.

[10] Silitonga, P. D. P., \& Damanik, R. (2016). Implementasi Algoritma K-Means Clustering Pada Analisis Penyebaran Penyakit Pasien Pengguna Badan Penyelenggara Jaminan Sosial Kesehatan (BPJS). Jurnal Teknik Informatika UNIKA Santo Thomas. https://doi.org/10.17605/JTI.V1I2.34.G39t.

[11] Sumadikarta, I., \& Abeiza, E. (2014). PENERAPAN ALGORITMA K-MEANS PADA DATA MINING UNTUK MEMILIH PRODUK DAN PELANGGAN POTENSIAL (Studi Kasus: PT Mega Arvia Utama). Jurnal Satya Informatika

[12] Nababan, Darsono, and Justin Eduardo Simarmata. "Analysis Of Student Satisfaction With Academic Services Using Fuzzy Mamdani Method." Solid State Technology 63.3 (2020): 5069-5075. 